\title{
Transcriptome analysis reveals the roles of stem nodes in cadmium transport to rice grain
}

\author{
Ailing Liu', Zhibo Zhou', Yake Yi and Guanghui Chen ${ }^{2,3^{*}}$ (1)
}

\begin{abstract}
Background: Node is the central organ of transferring nutrients and ions in plants. Cadmium (Cd) induced crop pollution threatens the food safety. Breeding of low $\mathrm{Cd}$ accumulation cultivar is a chance to resolve this universal problem. This study was performed to identify tissue specific genes involved in $\mathrm{Cd}$ accumulation in different rice stem nodes. Panicle node and the first node under panicle (node I) were sampled in two rice cultivars: Xiangwanxian No. 12 (low Cd accumulation cultivar) and Yuzhenxiang (high Cd accumulation cultivar). RNA-seq analysis was performed to identify differentially expressed genes (DEGs) and microRNAs.

Results: Xiangwanxian No. 12 had lower Cd concentration in panicle node, node I and grain compared with Yuzhenxiang, and node I had the highest Cd concentration in the two cultivars. RNA seq analysis identified 4535 DEGs and 70 miRNAs between the two cultivars. Most genesrelated to the "transporter activity", such as OsIRT1, OsNramp5, OsVIT2, OsNRT1.5A, and OsABCC1, play roles in blocking the upward transport of Cd. Among the genes related to "response to stimulus", we identified OsHSP7O and OsHSFA2d/B2C in Xiangwanxian No. 12, but not in Yuzhenxiang, were all down-regulated by Cd stimulus. The up-regulation of miRNAs (osa-miR528 and osa-miR408) in Xiangwanxian No. 12 played a potent role in lowering $\mathrm{Cd}$ accumulation via down regulating the expression of candidate genes, such as bZIP, ERF, MYB, SnRK1 and HSPS.

Conclusions: Both panicle node and node I of Xiangwanxian No. 12 played a key role in blocking the upward transportation of $\mathrm{Cd}$, while node I played a critical role in Yuzhenxiang. Distinct expression patterns of various transporter genes such as OsNRT1.5A, OsNramp5, OsIRT1, OsVIT2 and OsABCC1 resulted in differential Cd accumulation in different nodes. Likewise, distinct expression patterns of these transporter genes are likely responsible for the low $\mathrm{Cd}$ accumulation in Xiangwanxian No. 12 cultivar. MiRNAs drove multiple transcription factors, such as OsbZIPs, OsERFs, OsMYBs, to play a role in Cd stress response.
\end{abstract}

Keywords: RNA-seq, Cadmium, Panicle node, Node I, Low cadmium accumulation

\section{Background}

Rice (Oryza sativa) is one of the largest food crops in China, accounting for $60 \%$ of the basic food supply. In recent years, an increasing area of rice fields in China has been contaminated by heavy metal cadmium $(\mathrm{Cd})$. In the 2010s, the reduction of annual grain production

\footnotetext{
* Correspondence: cgh68@163.com

${ }^{2}$ College of Agronomy, Hunan Agricultural University, Changsha, Hunan 410128, People's Republic of China

${ }^{3}$ Southern Regional Collaborative Innovation Center for Grain and Oil Crops (CICGO), Hunan Agricultural University, Changsha 410128, People's Republic of China

Full list of author information is available at the end of the article
}

by heavy metal pollution is about 100 billion tons [1] Cd pollution has caused an irreversible and difficult problem in rice production in China, especially in the southern regions. Physical, chemical, and phytoremediation strategies have been widely used to treat $\mathrm{Cd}$ contaminated soils, but little was recovered due to the high technical difficulties or costs. Therefore, it remains an urgent issue in solving the problem of $\mathrm{Cd}$ pollution.

Plants have evolved a plethora of genetic and metabolic mechanisms against $\mathrm{Cd}$ stresses. The Cd accumulation capacity in different rice varieties varies greatly $[2$, $3]$. One of the possible solutions for alleviating $\mathrm{Cd}$ contamination in rice is to cultivate varieties with less $\mathrm{Cd}$ 
accumulation in grains. The use of molecular and transgenic technologies coupled with next-generation sequencing (NGS) could facilitate the identification of genes and mechanisms potentially involved in the translocation, detoxification, immobilization, and allocation of $\mathrm{Cd}$ in different species and cultivars [4-7]. Recently, some genes involved in $\mathrm{Cd}$ uptake, transport and accumulation had been identified and used as targets of genetic manipulation [8-10]. Zhang et al. (2010) found that the $B a n C n . A B C C 3$ played a pivotal role in $\mathrm{Cd}$ resistance in rapeseed by blocking $\mathrm{Cd}$ transport to seeds and retaining $\mathrm{Cd}$ in the root pectin and shoot vacuoles [5]. Luo et al. (year) found that the loss-of-function mutation of Arabidopsis PLANT DEFENSIN 2 (AtPDF2.5) reduced Cd accumulation and enhanced $\mathrm{Cd}$ resistance in Arabidopsis root by chelating Cd [4]. Besides, CAL1 also plays a role in $\mathrm{Cd}$ transport by chelating $\mathrm{Cd}$ ion in the cytoplasm and facilitating $\mathrm{Cd}$ secretion to extracellular space [11]. However, the limited number of genes is insufficient to fully understand the biological processes of Cd transport and accumulation in plants.

Studies have shown that node is a pivotal location for nutrient distribution in graminaceous plants [12]. Both root and node are key barriers to $\mathrm{Cd}$ transport into rice grains [13]. Node is a central organ for xylem-tophloem transfer of nutrients, ions, and metabolites [12]. Stem nodes play a vital role in Cd transfer from soil to grains [14]. Genetic manipulation of the transporters in stem-portion might prevent the distribution of toxic heavy metals, like $\mathrm{Cd}$, into grains [15]. Feng et al. (2017) reported that the $\mathrm{Cd}$ concentration profiles were distinct in different part of rice, including stem nodes [13]. They showed that node I had higher capacity in $\mathrm{Cd}$ sequestration and detoxification, and node I had higher expression of genes associated with glycolysis and detoxification. Fujimaki et al. (2010) found that $\mathrm{Cd}$ accumulated most intensively in rice nodes [14]. These results indicate the multifaceted roles of plant nodes in $\mathrm{Cd}$ accumulation and detoxification. However, little is known about how differentially expressed genes (DEGs) related to $\mathrm{Cd}$ transport and enrichment of $\mathrm{Cd}$ in rice nodes.

Rice variety "Xiangwanxian No. 12" with low Cdaccumulation and "Yuzhenxiang" with high Cd accumulation in the grains were identified in previous study [16]. In this study, we performed deep sequencing analysis to identify DEGs and miRNAs (DEmiRNAs) between node I and panicle node from the two cultivars with and without-Cd stress. Through bioinformatics analysis, the key candidate genes, miRNAs, and biological processes in response to $\mathrm{Cd}$ stress were deciphered. These results are useful in the future elucidation of the molecular mechanisms of $\mathrm{Cd}$-accumulation and transport to rice grains.

\section{Results}

\section{Cd accumulation during cd-stress}

Under the control condition, node I (marked as "N") in the two cultivars $[21.05 \mathrm{mg} / \mathrm{kg}$ DW (Dry Weight) in "Yuzhenxiang" as "y" and $10.25 \mathrm{mg} / \mathrm{kg}$ DW in "Xiangwanxian No. 12" as "X"] had higher Cd accumulation compared with panicle node (marked as "P", $2.17 \mathrm{mg} / \mathrm{kg}$ DW in " $y$ " and $1.40 \mathrm{mg} / \mathrm{kg}$ DW in "X"; $p<0.01$, Fig. 1a). The Cd stress increased the $\mathrm{Cd}$ accumulation in all tissues, especially in the node I $(56.43 \mathrm{mg} / \mathrm{kg}$ DW in " $\mathrm{y}$ " and $44.25 \mathrm{mg} / \mathrm{kg}$ DW in "X"). Grains of "X" cultivar had lower $\mathrm{Cd}$ content (both in control and $\mathrm{Cd}$ treatment) than that in " $y$ " cultivar. These data confirmed that " $y$ " was a high $\mathrm{Cd}$ accumulation cultivar, and node I had higher capacity in $\mathrm{Cd}$ sequestration. In addition, the expression of OsMAPK, OsHMA3, OsZIP4 and OsPCS showed different profiles in different groups (Fig. 1b to e). OsMAPK showed a higher expression (mean value) after Cd treatment in panicle node and node I of " $\mathrm{X}$ " and " $\mathrm{".} \mathrm{Additionally,} \mathrm{the} \mathrm{expression} \mathrm{of} \mathrm{OsMAPK} \mathrm{in} \mathrm{"} \mathrm{X}$ " was higher than that in " $y$ " (Fig. 1b). We found that the expression of OsHMA3 was increased by $\mathrm{Cd}$ stress in panicle node, not in node I (Fig. 1c). While OsZIP4 and OsPCS showed no differences among different groups (Fig. 1d and e).

\section{Summary of the mRNA-seq and miRNA-seq}

Twenty-four cDNA libraries were constructed and a total of $1111.34 \mathrm{M}$ clean reads obtained with $89.80 \%$ average mapping rate $(76.45-92.37 \%)$ to the rice reference genome (Additional file 2: Table S1). Principle component analysis (PCA) (Fig. 2a) and sample-tosample clustering analysis (Fig. 2b) showed that the samples of the same tissue ("P" or "N") from the same cultivar of control ("C") and $\mathrm{Cd}$ treatment ("T") were clustered together, respectively. Twenty-four miRNA libraries generated total $350.83 \mathrm{M}$ clean reads $(112.57 \mathrm{M}$ unique reads) with an averaged mapping rate of $82.01 \%$ to the O. sativa reference miRNA in miRbase (http:// www.mirbase.org/cgi-bin/mirna_summary.pl?org=osa). The alignment rate of each sample ranged from 0.62 to $2.37 \%$ in miRBase (average 1.49\%, Additional file 2: Table S1). PCA and sample-to-sample clustering analysis showed that samples of the same tissue ("P" or "N") were grouped together (Fig. 2c and d).

\section{DEGs between high and low cd accumulation cultivars}

A total of 4535 DEGs were identified by pairwise comparison of Cd-treated $(\mathrm{T})$ vs. untreated control $(\mathrm{C})$ of node I $(\mathrm{N})$ and panicle node $(\mathrm{P})$ in "X" and " $\mathrm{y}$ " cultivar, respectively (Fig. 3a-b and Table 1). The results showed that there were more down-regulated genes in " $\mathrm{X}$ " cultivar than that in " $y$ " cultivar. GO and KEGG enrichment based on these down regulated genes were performed to 

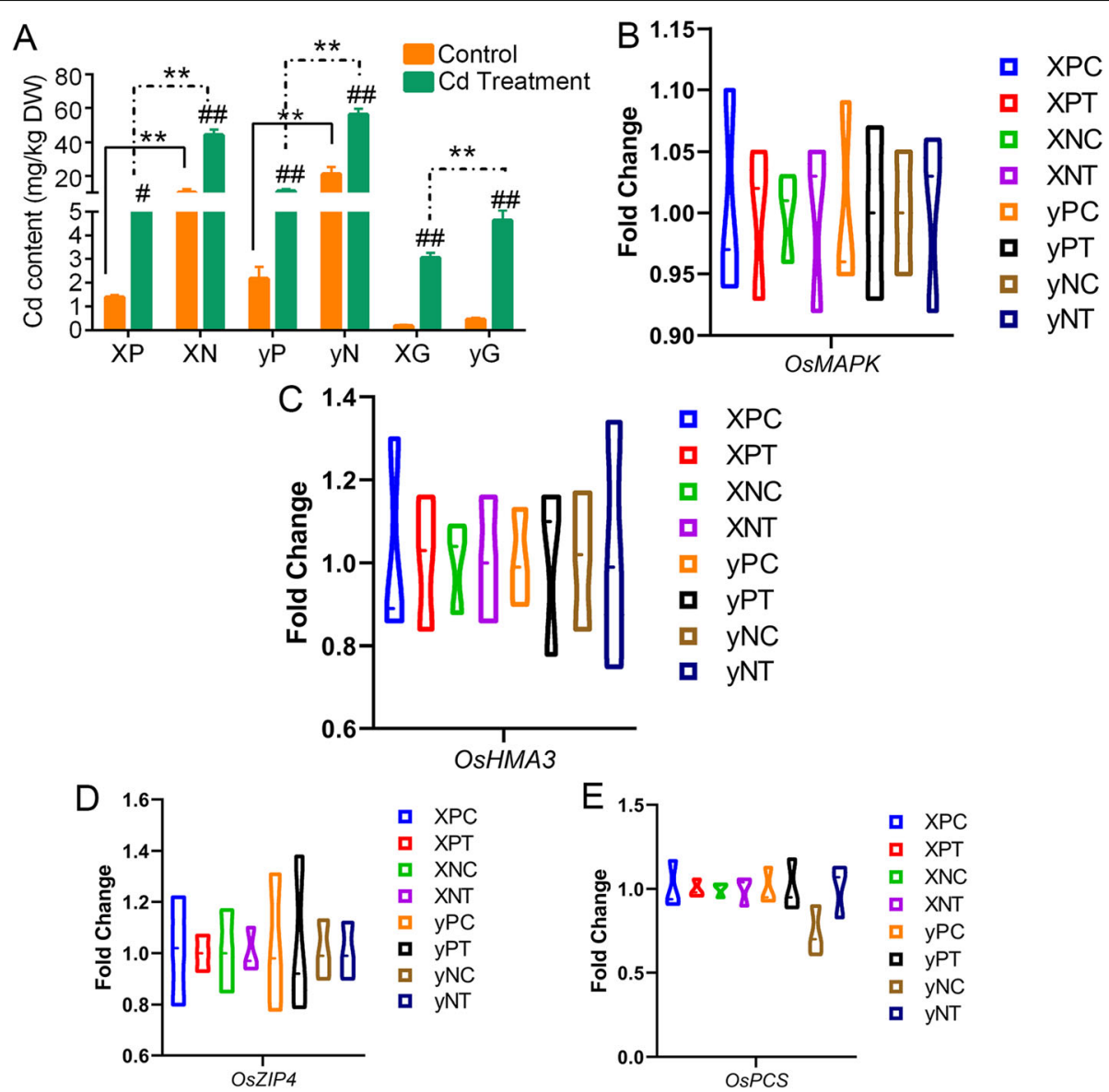

Fig. $1 \mathrm{Cd}$ contents and regulator expression profiles in these two rice varieties. a shows the $\mathrm{Cd}$ contents in different stem nodes and grain. DW, dry weight (kg); XP, panicle node of Xiangwanxian No.12; XN, node I of Xiangwanxian No.12; yP, panicle node of Yuzhenxiang; yN, node I of Yuzhenxiang; XG, grain of Xiangwanxian No.12; yG, grain of Yuzhenxiang. \# $p<0.05, \# \# p<0.01$ Cd treatment vs. control; ${ }^{*} p<0.01,{ }^{* *} p<0.05 y$ (Yuzhenxiang) vs. X (Xiangwanxian No.12). b to e show the interleaved violin plot of the expression of OsMAPK, OsHMA3, OsZIP4 and OsPCS, respectively

identify the main biological processes. The results showed that GO terms of "transporter activity" and "response to stimulus" were significantly enriched in " $\mathrm{X}$ ", not in "y" (Fig. 4a). Results of hierarchical clustering analysis of the 84 common DEGs (including 69 genes down regulated by $\mathrm{Cd}$ stress in "X") showed an enrichment in "transporter activity" (Fig. 4b and Additional file 3: Table S2), whereas another 74 common DEGs (including 62 genes down regulated by $\mathrm{Cd}$ treatment in "X") were enriched in "response to stimulus" (Fig. 4c and Additional file 4: Table S3). Notably, most of the DEGs in " $\mathrm{X}$ " were down-regulated by $\mathrm{Cd}$ treatment, and most down-regulated genes in "X" by $\mathrm{Cd}$ treatment were unchanged in " $y$ ", especially for the DEGs associated with "response to stimulus" (Fig. 4c). Most of the DEGs mentioned above were differently expressed in different stem nodes (Fig. 4c and d).

The iron-regulated transporter 1 (IRT1, OS03G0667500) [17] and metal transporter Nramp5 (Mn and Cd uptake protein, OS07G0257200) [18-20] were noteworthy as they had higher expression in the panicle node compared with node I (Additional file 3: Table S2). For node I, OsIRT1 and OsNramp5 increased in " $\mathrm{X}$ ", while decreased in " $\mathrm{y}$ " cultivar (Additional file 1: Figure S1 A). Although the expression of OsIRT1 and OsNramp5 increased after $\mathrm{Cd}$ treatment, overall it remained at a low level in "X" cultivar.

The expression patterns of OsNRT1.5A (OS02G0689900, nitrate transporter 1.5A) and OsVIT2 (OS09G0396900, Vacuolar Iron Transporter 2) implied its key role in the upward transport of $\mathrm{Cd}[21,22]$. OsNRT1.5A had a higher expression level in node I than that in panicle node in both two cultivars. In the panicle node, OsNRT1.5A was downregulated in "X" but up-regulated in " $\mathrm{y}$ " under Cd stress. OsVIT2 was up-regulated following $\mathrm{Cd}$ treatment in node I in both cultivars, but down-regulated in panicle node in the "X" cultivar. Cd stress had little effects on the expression level of OsVIT2 in panicle node in "y" cultivar (Additional file 1: Figure S1 A and Additional file 3: Table S2). 


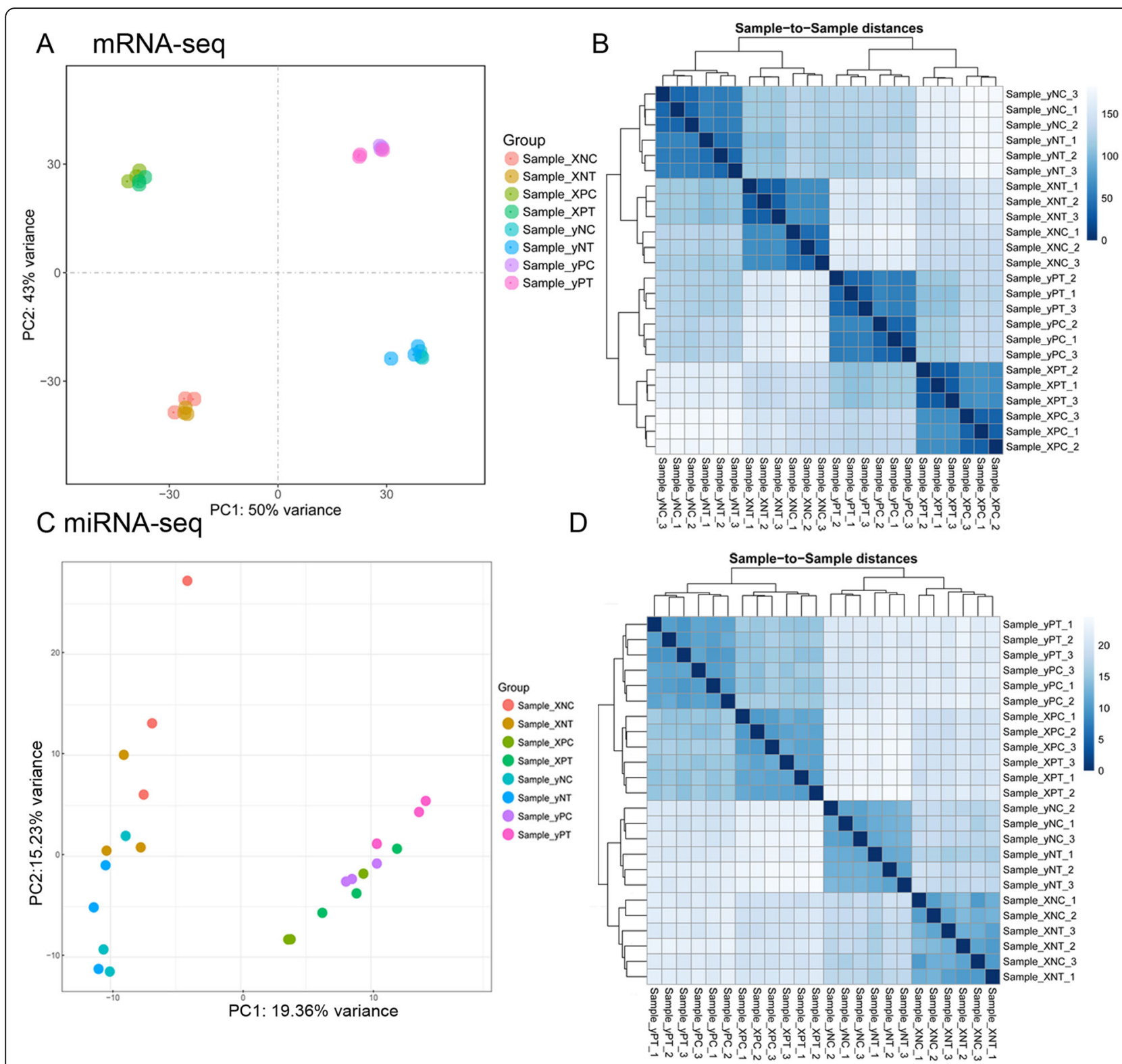

Fig. 2 Sample clustering and correlation analysis. a and $\mathbf{c}$ the principal component analysis (PCA) of the samples sequenced using the mRNA and miRNA expression level, respectively. $\mathbf{b}$ and $\mathbf{d}$ the sample-to-sample clustering analysis based on the mRNA and miRNA expression level, respectively. The color depth notes the similarity between samples $(0 \sim 1)$. The deeper the color, the higher the similarity

Aquaporin protein is closely related to heavy metal stress, with distinct expression patterns in different plant species [23-27]. In our results, 6 aquaporin genes (PIPs) (OS02G0629200, OsPIP2-6; OS04G0233400, OsPIP2-6; OS02G0666200, OsPIP1-1; OS04G0559700, OsPIP1-2, OS07G0448100, OsPIP2-4; OS07G0448800, OsPIP2-1) showed similar expression profiles under $\mathrm{Cd}$ stress (Additional file 1: Figure S1 B). The expression of 6 PIPs members was higher in " $\mathrm{X}$ " than in " $\mathrm{y}$ " cultivar under control condition, and down regulated after $C d$ treatment in " $X$ ", but with little changes in " $\mathrm{y}$ ". The expression of OsPIPs show no significant differences between node I and panicle node in " $\mathrm{X}$ " and " $\mathrm{y}$ ".

Among the DEGs related to "response to stimulus", heat shock transcription factor (HSF) $A 2 d / B 2 c$ genes (including OS03G0161900/OS09G0526600), lightharvesting chlorophyll a-b binding protein (LHC-II) genes (e.g. OS02G0197600), and genes encoding heat shock protein (HSP71.1/70/20; including OS03G0276500, OS01G0840100 and OS06G0253100) showed similar changes in the panicle node and node I of the two rice cultivars (Additional file 4: Table S3). 

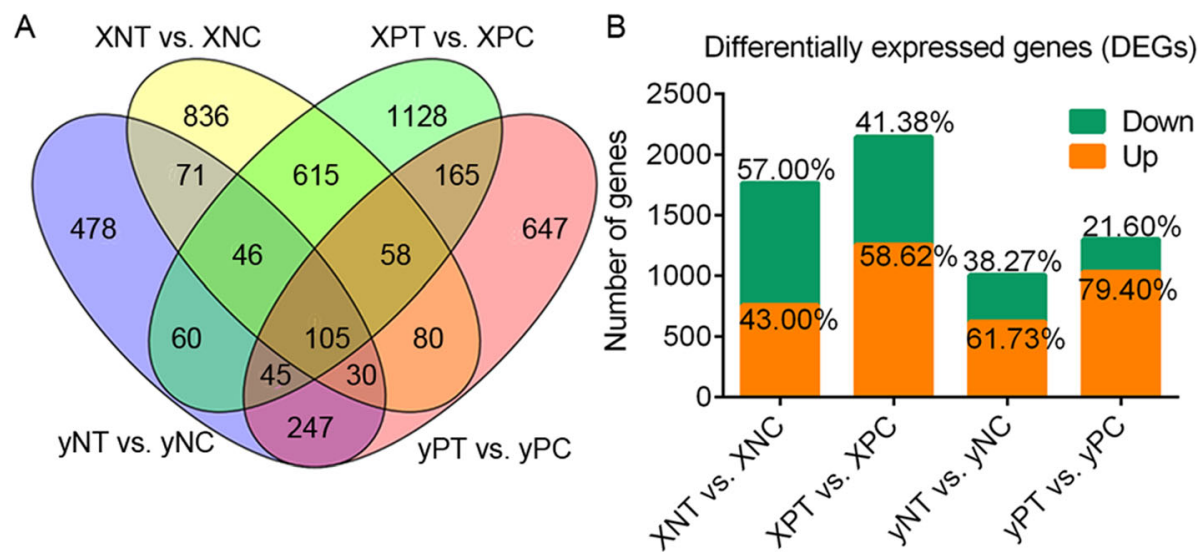

Fig. 3 Summary of differentially expressed genes (DEGs). a The Venn figures of the DEGs in pairwise comparison of Cd-treated (T) vs. untreated control (C) of node I (N) and panicle node (P) in " $X$ " and " $y$ " cultivar, respectively. $\mathbf{b}$ the statistics of the up- and down-regulated DEGs. The number on the column indicates the percent of the up and down-regulated DEGs by each comparison

Higher expression levels of aforementioned genes were found in " $\mathrm{X}$ " than in " $\mathrm{y}$ " cultivar (Additional file 1: Figure $\mathrm{S} 1 \mathrm{C}) . \mathrm{Cd}$ treatment decreased the expression of all these genes in the " $\mathrm{X}$ " cultivar, but increased OsHSFA2d/B2c, OsLHC-II and OsHSP71.1 in the panicle node of " $y$ " cultivar. The distinct expression profiles of these DEGs mentioned above are likely account for, or in part, the differential $\mathrm{Cd}$ accumulation between the two rice cultivars.

\section{Expression of known cd-responsive genes}

In order to decipher the DEGs expression pattern in different stem nodes under $\mathrm{Cd}$ stress, we analyzed the expression profiles of $52 \mathrm{Cd}$-responsive genes reported previously in the literature. Among these genes, metallothionein 1 (OsMT1) [28], cadmium tolerant 1 (OsCDT1), OsCDT2 [29, 30], OsMTP1 [7], cation diffusion facilitator (OsCDF1), ATP-binding cassette transporter multidrug resistance protein 1 (OsMRP1/ABCC1) [31, 32] showed higher expression levels in the two rice cultivars. Furthermore, they expressed higher in the panicle node of the two cultivars compared with node I (Fig. 5). Cd

Table 1 Statistics of the differentially expressed genes (DEGs) and miRNAs (DEmiRNAs) by different pairwise comparison

\begin{tabular}{llllllll}
\hline \multicolumn{2}{l}{ Comparison } & DEG & & \multicolumn{4}{l}{ DEmiRNAs } \\
\hline Case & Control & Up & Down & Total & Up & Down & Total \\
XNT & XNC & 759 & 1006 & 1765 & 20 & 10 & 30 \\
XPT & XPC & 1258 & 888 & 2146 & 11 & 14 & 25 \\
yNT & yNC & 621 & 385 & 1006 & 15 & 10 & 25 \\
yPT & yPC & 1033 & 268 & 1301 & 18 & 8 & 26 \\
\hline
\end{tabular}

"X" notes low Cd accumulation cultivar "Xiangwanxian No. 12", " $y$ " notes high $\mathrm{Cd}$ accumulation cultivar "Yuzhenxiang", " $\mathrm{P}$ " indicates panicle node, " $\mathrm{N}$ "

indicates the first node, " $\mathrm{C}$ " represents control and " $\mathrm{T}$ " represents $\mathrm{Cd}$ treatment stress enhanced the expression of OsCDT1 and $O s A B C C 1$ in the node I of " $\mathrm{X}$ " cultivar. Another gene serine hydroxymethyltransferase 1 (OsSHM1), which showed relatively higher expression level, was down regulated only in the panicle node of " $\mathrm{X}$ " cultivar by $\mathrm{Cd}$ stimulus (Fig. 5). In addition, the OsNAS3 (nicotinamine synthase 3) and OsDEP1 (dense and erect panicle 1) showed relatively high expression in node I of the two cultivars. Cd treatment increased the expression of OsNAS3 and OsMT1d in node I and both nodes, respectively (Fig. 5). Other Cd-responsive genes including OsMT1f, OsYSL15, OsIRT2, and OsGST4 had low expression levels in the two cultivars, which were unresponsive to Cd stress in our study.

\section{Identification of differentially expressed DEmiRNAs}

A total of 70 non-overlapping DEmiRNAs were identified from panicle node and node $I$ in the two rice cultivars (Fig. 6a and Additional file 5: Table S4). Most DEmiRNAs were up-regulated by $\mathrm{Cd}$ treatment. There were $12 \mathrm{com}$ mon DEmiRNAs among all the pairwise comparisons (Fig. 6b), of which six miRNAs (osa-miR398b, osa-miR408-3p, osa-miR408-5p, osa-miR528-5p, osa-miR528-3p and novel50_mature) were up-regulated by $\mathrm{Cd}$ treatment (Fig. 6c). In addition, only one common DEmiRNA (osamiR528-3p) was identified as Cd up-regulated in the panicle node of both cultivars. There were six common DEmiRNAs (osa-miR408-3p, osa-miR408-5p, osa-miR528$5 p$, osa-miR398b, osa-miR166-5p and novel50_mature) in node I of both cultivars, among which, only osa-miR166$5 p$ showed a different expression pattern in node I of " $\mathrm{X}$ " cultivar and panicle node of " $y$ " cultivar. In order to reveal the differential expression profiles of microRNAs more comprehensively, we screened the other miRNA family members (Fig. 6d). Osa-miR398b, osa-miR408-3p, osa- 
A

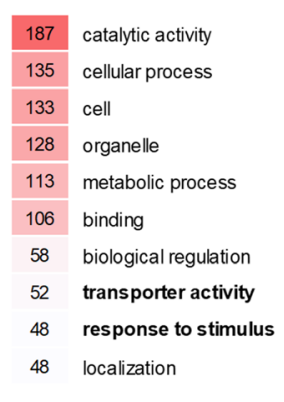

XNC vs. XNT

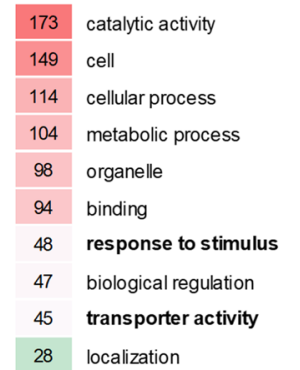

XPC vs. XPT

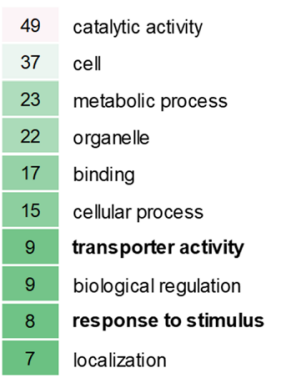

yNC vs. yNT

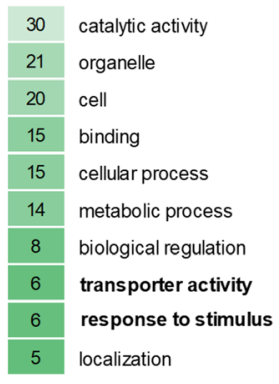

yPC vs. yPT
B

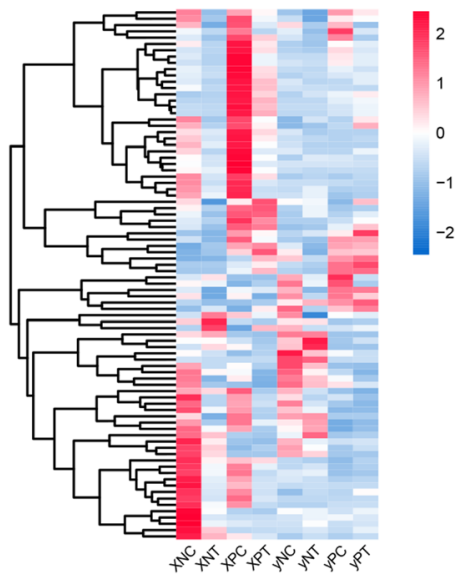

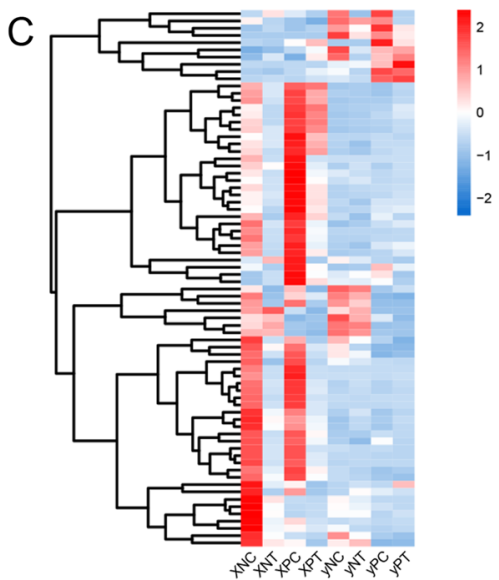

Fig. 4 Differentially expressed genes (DEGs) between high and low Cd accumulation cultivars. a Gene Ontology (GO) and KEGG pathway enrichment analyses of down-regulated DEGs in pairwise comparison of Cd-treated (T) vs. untreated control (C) of node I (N) and panicle node (P) in " $X$ " and " $y$ " cultivar, respectively. The redder the color, the more significantly enriched DEGs there were, the greener the color, the less; $\mathbf{b}$ and c Hierarchical clustering analysis of the DEGs involved in "transporter activity" (B) and "response to stimulus" (C), respectively

miR528-3p and osa-miR528-5p had a higher expression level in panicle node than that of node I under Cd stress. We then constructed the DE miRNA-mRNA regulatory network (Fig. 7) based on the 15 miRNA (12 common and 3 family members) and the targets among the downregulated DEGs. In the regulatory network, an HSP member (OS06G0253100) was regulated by two miRNAs including osa-miR528-5p and osa-miR5493. OsMYB5P (OS02G0624300), OsbZIP18 (Os02g0203000), and OsERF141 (Os02g0638650) were regulated by osa$m i R 528-5 p$ and novel13_mature, indirectly. Another bZIP member OsbZIP23 (Os02g0766700) was the target gene of osa-miR1846a/b/c-5p; SNF1-related protein kinase 1 subfamily protein (SnRK) gene (OS02G0178000, OsSnRK1) was regulated by osa-miR528-3p. In addition, OsAAE3 (OS04G0683700) was regulated by both osa-miR408-3p and novel50_mature (Fig. 7 and Additional file 1: Figure S1D).

\section{qRT-PCR verification of RNA-seq data}

A total of 14 mRNA and 3 miRNAs were selected randomly for qRT-PCR analysis (Fig. 8a and c). The fold- changes of all the selected 14 mRNA and 3 miRNAs found in qRT-PCR and RNA-seq were highly consistent, and the correlation coefficient was 0.6 (Fig. 8c).

\section{Discussion}

Cd has serious influences on photosynthesis [33, 34], respiration [35], nutrient metabolism, distribution and ion transport in plants $[8,36-38]$. Identification of rice cultivars with low $\mathrm{Cd}$ accumulation in the grains is of highly theoretical and practical significant in rice breeding. Our present study confirmed that the node I of rice plant had a high capacity in Cd sequestration and accumulation. Results of our RNA-seq analyses indicated that different capacities in $\mathrm{Cd}$ accumulation between node I and panicle node were mediated by different gene expression pattern in different rice cultivars.

\section{Barring cd transport into rice grains}

The high $\mathrm{Cd}$ accumulation in the nodes and roots of rice has been reported by Feng et al. [13]. Node is the central organ of xylem to phloem transport of nutrients, ions, and metabolites [12]. It plays a vital 


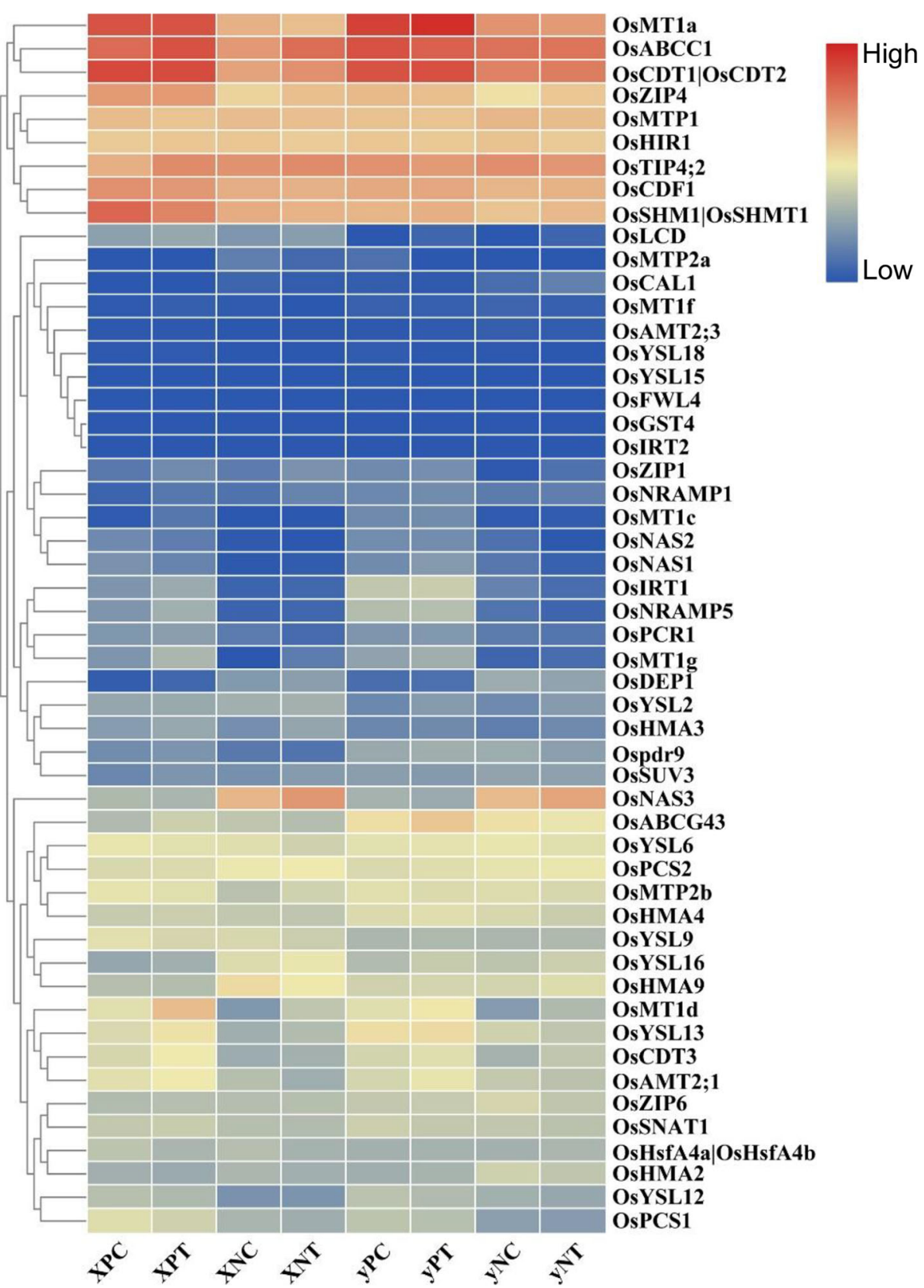

Fig. 5 Heatmap of known 52 Cd-responsive genes. These Cd-responsive genes were collected from previous literatures. The change of color from blue to red indicated that gene expression level was low to high

role in Cd transport from soil to grains [14]. Previous reports showed that the accumulation of heavy metals gradually decreased in successive nodes [13, 39-41]. $\mathrm{Cd}$ is transported upward and accumulated in nodes, distributed in the xylem elliptical vascular bundles and the surrounding parenchyma cell bridges [14, 39]. In the present study, the accumulation of $\mathrm{Cd}$ in nodes is obvious, consistent with a previous report [14]. But the content of $\mathrm{Cd}$ in different nodes is different, so the roles of different nodes in blocking the upward transport of $\mathrm{Cd}$ are distinct. The high $\mathrm{Cd}$ content in node I indicated that most $\mathrm{Cd}$ was blocked here during upward transport. The $\mathrm{Cd}$ transport was subsequently blocked in panicle node, although to a lesser extent. Therefore, it appears that the upward transport of $\mathrm{Cd}$ decreases step by step from node I to panicle node, so the concerted effect of the two nodes is important for the interception of $\mathrm{Cd}$ in rice stem. 


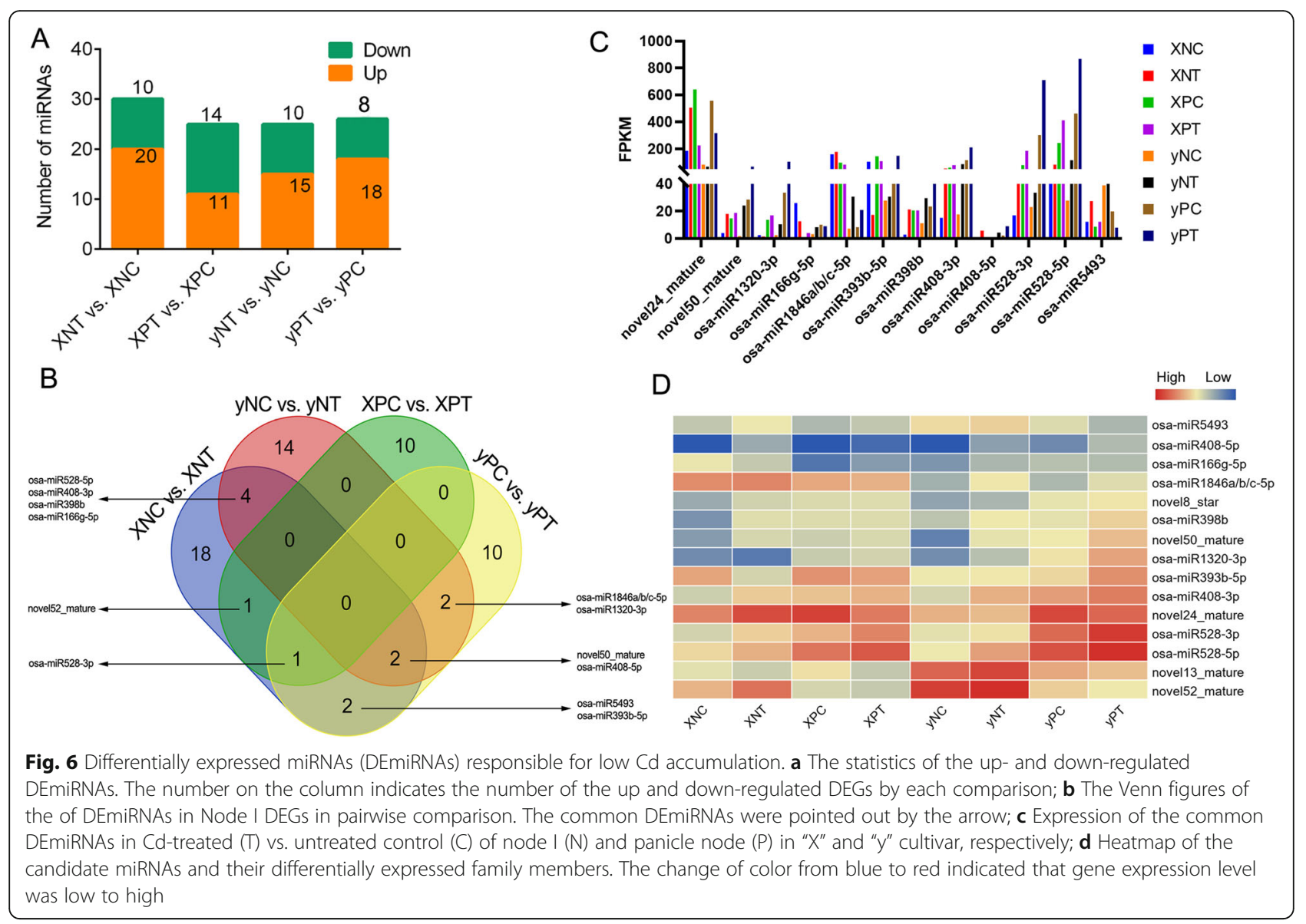

Key genes mediating the cd transport and accumulation in rice node I and panicle node

Using the transcriptome data, we identified several key genes might be responsible for the $\mathrm{Cd}$ accumulation in node I and panicle node. For panicle node, compared with the high $\mathrm{Cd}$-accumulation cultivar " $\mathrm{y}$ ", low $\mathrm{Cd}$ accumulation cultivar " $X$ " had lower expression of OsIRT1 and OsNramp5, but higher expression of OsVIT2 and OsNRT1.5A. Nramp5 is an $\mathrm{Mg}$ and $\mathrm{Cd}$ transporter as well as $\mathrm{Mn}$ and $\mathrm{Cd}$ uptake protein. The uptake of $\mathrm{Cd}$ into the root cells is primarily mediated by OsNramp5, which showed higher transport activity than its counterpart in wheat or maize [18-20]. The knockout or loss-of-function mutation of OsNramp5 dramatically reduced the accumulation of $\mathrm{Cd}$ and $\mathrm{Mn}$ without compromising yield [18, 42]. Compared with OsNramp5, OsIRT1 has a relatively small contribution to Cd uptake [17]. Cd stress reduced the expression of OsNramp5 and OsIRT1 in node I of " $\mathrm{y}$ ", which indicated that the Cd intake capacity faded. As for "X", OsNramp5 and OsIRT1 were up-regulated in both node I and panicle node after Cd treatment, of which the expression still at a low level, although they were increased. This indicated that the response patterns of OsNramp5 and OsIRT1 to Cd stress were distinct between " $\mathrm{X}$ " and " $\mathrm{y}$ ", especially in node $\mathrm{I}$. It is likely that " $\mathrm{X}$ " cultivar reduces $\mathrm{Cd}$ intake by maintaining a low expression level of OsNramp5 and OsIRT1 in both node I and panicle node, while " $y$ " cultivar blocked Cd uptake mainly by reducing OsNramp5 expression in node $\mathrm{I}$.

VIT2 regulates metal sequestration into vacuoles. VIT2 is up-regulated when excessive metals are available in the environment. The enhanced VIT2 expression consequently leads to higher vacuolar sequestration capacity and metal accumulation in vacuoles [43-45]. Similar to OsVIT2, OsABCC1 can concentrate heavy metal ions in vacuoles and prevent it from upward transport to the grains [5, 32, 46]. Our transcriptome data showed that OsVIT2 was up- and down-regulated in node I and panicle node in "X" cultivar, respectively. As for " $y$ ", there were little changes in the expression of OsVIT2. In particular, the expression of OsVIT2 in node I of " $y$ " maintained a higher level than " $\mathrm{X}$ ", which might explain the high content of $\mathrm{Cd}$ in " $\mathrm{yN}$ ". In addition, the expression of OsABCC1 was induced by $\mathrm{Cd}$ treatment in " $\mathrm{X}$ ", but not in " $y$ " cultivar (Fig. 5). The enhanced expression of 


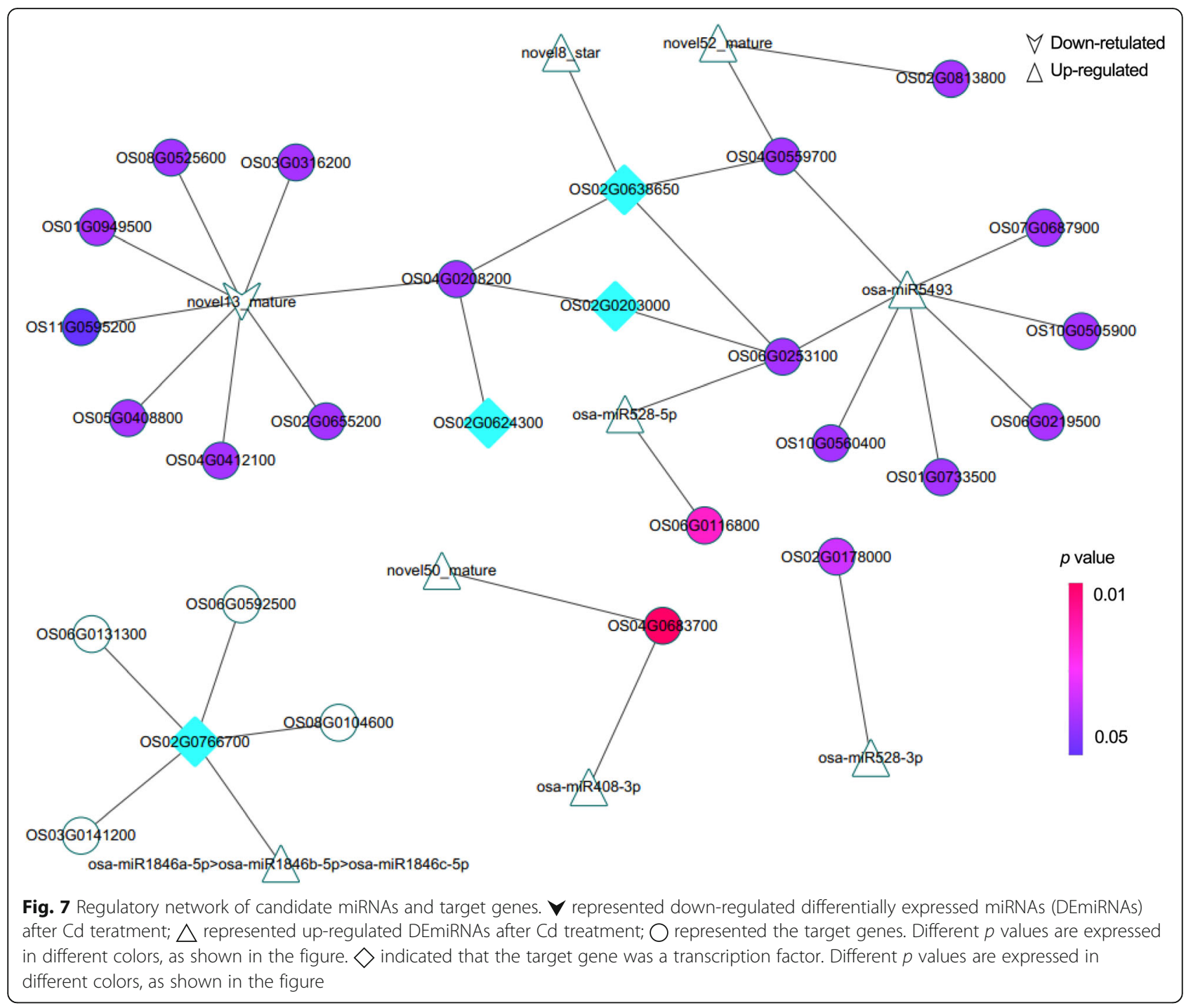

OsABCC1 might contribute to the relatively low $\mathrm{Cd}$ accumulation in grains of " $\mathrm{X}$ " cultivar.

NRT1.5A mediated nitrate distribution plays a role in plant tolerance to $\mathrm{Cd}$ stress [47]. The $\mathrm{NO}_{3}{ }^{-}$negatively affects $\mathrm{Cd}$ uptake in plant roots $[48,49]$. In our results, the expression pattern of OsNRT1.5A was completely different in different nodes. OsNRT1.5A in node I was several times higher than that in panicle node, which implicated that OSNRT1.5A mainly played a role in node I. Cd treatment enhanced OsNRT1.5A expression in node I in "X" cultivar, but not in " $y$ " cultivar, which revealed a differential response in the two rice cultivars. Because NRT1 negatively regulates the uptake of $\mathrm{Cd}$ and other cations by simultaneously uptake of $\mathrm{NO}_{3}{ }^{-}$in Arabidopsis [48], our results could be explained by the same inference, as high expression of OsNRT1.5A would suppress Cd uptake in node I in " $\mathrm{X}$ " cultivar.
The concerted expression of aforementioned genes is likely to have a large impact on $\mathrm{Cd}$ accumulation in rice nodes and grains. The proposed mechanism is shown in Fig. 9.

\section{Key genes responded to the cd stimulus in node I and panicle node}

Among the DEGs related to "response to stimulus", OsHSFA2d/B2c, OsLHC-II, and OsHSPs (including OsHSP70 and OsHSP20.0) showed higher expression in the low Cd-accumulation " $\mathrm{X}$ " compared with high $\mathrm{Cd}$ accumulation " $y$ " cultivar (Additional file 4: Table S3, Additional file 1: Figure S1). The expression of all these genes was significantly reduced by $\mathrm{Cd}$ treatment in " $\mathrm{X}$ ", but showed small or undetectable changes in " $y$ " cultivar, indicating a relative insensitivity of " $y$ " cultivar to Cd stress (Additional file 4: Table S3, Additional file 1: 


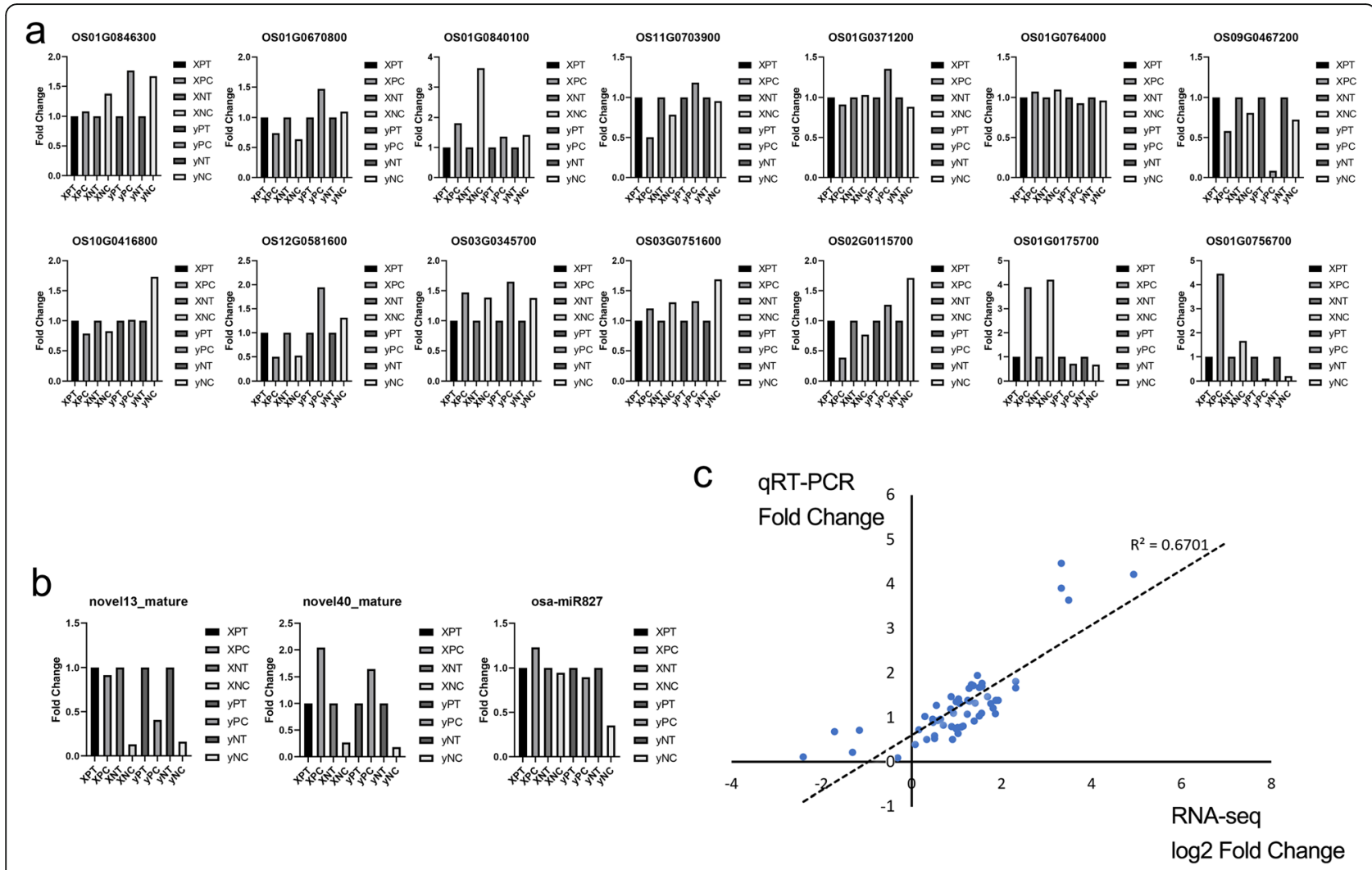

Fig. 8 Consistency results of qRT-PCR and RNA-seq. a Expression of mRNAs in different group. b Expression of miRNAs in different group. $\mathbf{c}$ Consistency results of qRT-PCR and RNA-seq (including mRNAs and miRNAs). The figure was based on the fold change of qRT-PCR and log2 fold change of RNA-seq. $R^{2}$ represented the correlation coefficient between qRT-PCR and RNA-seq

Figure S1). HSF and HSPs (large or small) play critical roles in plant immunity, growth, defense, and stress responses [50-53]. In rice, Cd-stress induces HSPs expression, in turns it inhibits Cd-induced damage in plant cells [54]. It has been reported that overexpression of HSP enhanced abiotic stress tolerance to heat, drought, abscisic acid, salinity and cold in rice [55]. Cai et al. (2017) reported that silencing of HSFA1a in tomato plants could block Cd uptake and reduce HSP expression, while HSFA1a overexpressing promoted HSP expression [53]. The unchanged expression of HSFs and $H S P$ indicated that " $\mathrm{y}$ " cultivar was insensitive to $\mathrm{Cd}$ stimulus. Likewise, the unchanged expression of OsLHCII might indicate more stable photosynthesis, growth, and development of "y" cultivar under $\mathrm{Cd}$ stimulus. In addition, 6 aquaporin genes (PIPS) were expressed at higher levels in " $\mathrm{X}$ " than that in " $\mathrm{y}$ " cultivar, and down regulated by $\mathrm{Cd}$ treatment only in "X", but not in " $\mathrm{y}$ " (Additional file 1: Figure S1 B). Heavy metal can cause water deficit in plants, which greatly affects plant growth and productivity. The expression of PIPs is closely related to heavy metal stress, with distinct expression patterns in different plant species [23-27]. Different reports have shown that heavy metals can trigger the closure of aquaporins due to their abilities to react with the $\mathrm{S}-\mathrm{H}$ group of the protein $[56,57]$. In " $X$ " cultivar, the expression of aquaporin genes was repressed by Cd stress, but no significant changes in "y" cultivar. The decreased expression of aquaporin genes triggered by heavy metals was similar to what Kholodova et al. (2011) reported [25]. The decreased activities of aquaporins lead to low transpiration rate, under which the essential mass apoplastic water flow, determined mainly by the rate of transpiration, was replaced by predominantly cell-to-cell symplastic transport [58], which is regulated at the level of membrane water channels. Our results also indicated that there were significant differences between the two rice cultivars in response to $\mathrm{Cd}$ stress.

Interaction relationship of miRNAs and mRNA in response to cd stress

Among all the DEmiRNAs related to $\mathrm{Cd}$ accumulation, we found osa-miR408-3p, osa-miR528-3p osa-miR528-5p were commonly up-regulated by $\mathrm{Cd}$ stress in both nodes of the two cultivars. The effect of osa-miR528-3p has not been studied till now. Both osa-miR528 and osa-miR408 


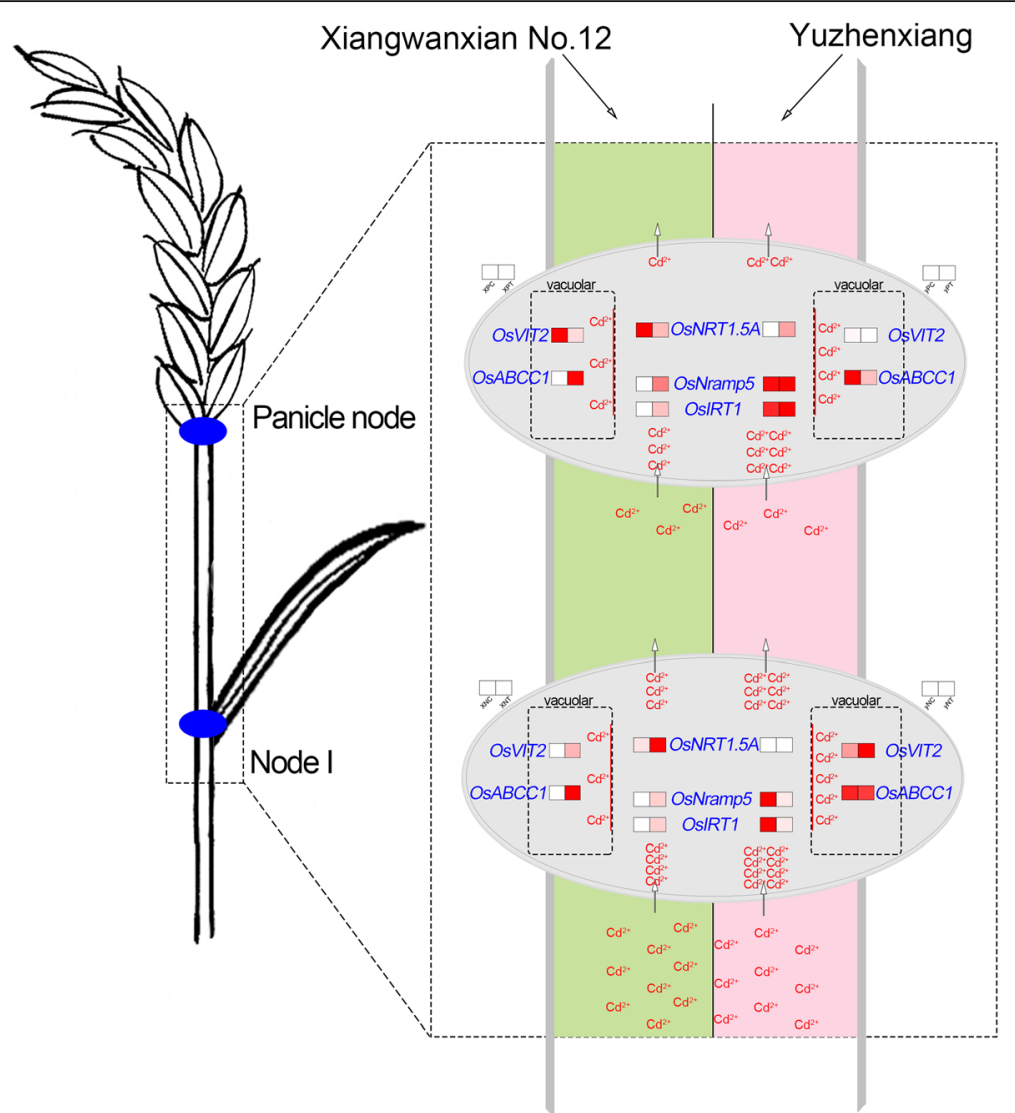

Fig. 9 Schematic maps of upward transport mechanism of blocking $\mathrm{Cd}$ in different rice varieties. Panicle node (P) and node I (N) were marked in blue on the rice sketch. The schematic map (the right of the figure) showed the upward transport mechanism of blocking Cd in Xiangwanxian No.12 (pale green) and Yuzhenxiang (pale pink). The ellipse at top and bottom represented panicle node and node I, respectively. The expression of key genes was showed by heatmap (box on left and right represented control and $\mathrm{Cd}$ treatment, respectively), the redder the color, the higher the expression. The direction of $\mathrm{Cd}$ transportation was indicated by arrows and the content of $\mathrm{Cd}$ was expressed by the number of " $\mathrm{Cd}{ }^{2+\prime \prime}$

family members were differentially expressed in response to abiotic stresses, such as drought [59], low temperature [60], heavy metal [61] and plant defense responses (the reference is about drought) [62]. Cheah et al. $(2015)$ showed that several miRNAs including osa-miR398, osamiR397, osa-miR408-5p and osa-miR528-5p were upregulated in the drought-susceptible rice variety [59]. This was also true for in cool-tolerant rice (Hitomebore) under cool-temperature [60]. The interaction network showed that 4 transcription factors (TFs), OsbZIP18, OsbZIP23, OsMYB5P and OsERF141, were potential target genes of aforementioned miRNAs. Interestingly, osamiR5493 also showed a negative relationship with OS06G0253100 (OsHsp20), OS02G0203000 (OsbZIP18) and OS02G0638650 (OsERF141) only in Xiangwanxian No.12. This implied that osa-miR5493 might also be a key regulator in response to $\mathrm{Cd}$ stress via regulating the expression of TFs. As we know, WRKY, bZIP, ERP and MYB proteins play an important role in controlling the expression of their downstream genes in response to $\mathrm{Cd}$ stress [63]. The down regulation of OsERFs and OsbZIPs was also found in another rice variety after $\mathrm{Cd}$ stress [64]. Expression of osa-miR5493 were up-regulated after $\mathrm{Cd}$ treatment in " $\mathrm{X}$ ". Correspondingly, the unchanged expression of osa-miR5493 and these four TFs further demonstrated that " $y$ " cultivar was insensitive to $\mathrm{Cd}$ stress. Consequently, we speculate that osa-miR5493 was an important miRNA in regulating the expression of OsERFs and OsbZIPs. SnRKs play an important role in plant biotic interaction in Arabidopsis thaliana. SnRK1 overexpression plants displayed enhanced resistance to geminivirus, while SnRK1 silenced plants were more susceptible than the wild-type plants $[65,66]$. The higher expression of OsSnRK1 in the panicle node suggests that panicle node is the key part of "X" cultivar in response to Cd stress. In addition, SnRKs are the upstream regulatory genes of HSPs in ABA signal transduction pathway $[67,68]$. Therefore, the expression changes of HSPs in panicle node of " $X$ " cultivar may be due to the action of OsSnRK1 and osa-miR5493. 


\section{Conclusions}

In this study, we have demonstrated that distinct $\mathrm{Cd}$ accumulation in the panicle node and node I in two different rice cultivars was mediated by different gene expression pattern. Both panicle node and node I of " $\mathrm{X}$ " cultivar played a key role in blocking the upward transportation of $\mathrm{Cd}$, while only node I played a critical role in " $\mathrm{y}$ " cultivar. We have identified a cluster of candidate genes which might be responsible for $\mathrm{Cd}$ accumulation in panicle node and node I. Most of these genes (OsIRT1, OsNramp5, OsVIT2, OsNRT1.5A, and OsABCC1) are related to the "transporter activity". The concerted action of these transporters could block the transport of $\mathrm{Cd}$ up to panicle and accumulation in the grains of low $\mathrm{Cd}$-accumulation cultivar. Among the DEGs related to "response to stimulus", we identified OsHSP7O and OsHSFA2d/B2c down regulated by $\mathrm{Cd}$ in " $\mathrm{X}$ ", but not in " $\mathrm{y}$ " cultivar. MiRNAs including osa-miR528, osa-miR408 and osa-miR5493 family members which were up-regulated by $\mathrm{Cd}$, showed potential roles in lowering $\mathrm{Cd}$ accumulation via regulating genes like $b Z I P, E R F, M Y B, S n R K 1$ and HSPs. The differential gene expression is likely responsible for the low $\mathrm{Cd}$ accumulation in " $\mathrm{X}$ " cultivar. These findings have provided novel insights into breeding new rice varieties with low $\mathrm{Cd}$ accumulation.

\section{Methods}

\section{Plant materials and treatment}

The seeds of two Chinese rice (O. sativa) cultivars "Xiangwanxian No. 12" (low Cd accumulation, " $\mathrm{X}$ " for short) and "Yuzhenxiang" (high Cd accumulation, " $\mathrm{y}$ " for short) were obtained from the germplasm recourses bank of Hunan rice research institute. All seeds were sterilized with prochloraz, soaked in deionized water at room temperature (RT) for $48 \mathrm{~h}$, and germinated at $30{ }^{\circ} \mathrm{C}$ for $24 \mathrm{~h}$, then sowed into the fields with normal standard conditions $\left(15-22^{\circ} \mathrm{C}\right.$ for nighttime and 20$25^{\circ} \mathrm{C}$ for daytime, without $\mathrm{Cd}$ stress) on 30th June in 2017. Seedlings with three true leaves were transplanted into pots $(54 \mathrm{~cm} \times 41 \mathrm{~cm} \times 23 \mathrm{~cm})$ with the density of 8 plants/4 holes/pot. Rice cultivars were sowed into the experimental pots full of muddy water without (control, "C" for short) or with $\mathrm{CdCl}_{2} \cdot 2.5 \mathrm{H}_{2} \mathrm{O}(15 \mathrm{mg} / \mathrm{Kg}$; treatment, "T" for short, last for about 4 months) [69]. Each cultivar was planted in 20 replications. Plants were managed with standard fertilization (compound fertilizer $\mathrm{N}$ : $\mathrm{P}_{2} \mathrm{O}_{5}: \mathrm{K}_{2} \mathrm{O}$ 15:8:12, $3 \mathrm{~g} /$ pot) was applied on July 5, 2017; urea was applied on August 16, 2017, $0.6 \mathrm{~g} / \mathrm{pot}$ ) The panicle node ("P" for short) and node I ("N" for short) were collected at grain-filling stage on November 9, 2017. Stem nodes (about $0.3 \mathrm{~cm}$ length) were sampled from fresh, leafless stems and snap-frozen in liquid nitrogen. According to the treatment strategies and sampling positions, the group samples were named as XPC,
XPT, yPC, yPT, XNC, XNT, yNC and yNT, where " $\mathrm{X}$ " notes "Xiangwanxian No. 12", "y" notes "Yuzhenxiang", "P" indicates panicle node, "N" indicates node I, "C" represents control and " $\mathrm{T}$ " represents $\mathrm{Cd}$ treatment. Liquid nitrogen flash frozen samples were stored at $-80^{\circ} \mathrm{C}$ before the extraction of RNA. Each sample was pooled by tissues from 3 to 5 individuals, and three repetitive samples were prepared for RNA isolation.

\section{Determination of $\mathrm{cd}$ concentration}

The accumulation of $\mathrm{Cd}$ in rice " $\mathrm{P}$ " and " $\mathrm{N}$ " tissues and grain were determined by atomic absorption spectrophotometer (PerkinElmer PinAAcle $900 \mathrm{~T}$, USA). Tissues were drying in a drying box $\left(105^{\circ} \mathrm{C}\right.$ for $30 \mathrm{~min}$ and at $80^{\circ} \mathrm{C}$ to constant weight). $50 \mathrm{mg}$ powder samples were immersed into $1 \mathrm{~mL} \mathrm{HNO}_{3}$ and digested to transparent solutions. Cooled samples were then diluted into water to a final volume of $13.5 \mathrm{~mL}$. Standard Cd solution was used as quality control samples. Besides, the expression of OsMAPK, OsHMA3, OsZIP4 and OsPCS were detected by qRT-PCR method.

\section{RNA extraction and libraries construction}

Total RNA was extracted from collected samples from two cultivars using TRIzol (Invitrogen, USA). The purification, qualification and quantification were conducted (DNase I, Invitrogen) by Agilent 2100 Bioanalyzer (Agilent Technologies, USA). For the preparation of the miRNA-seq, total RNA fragmentation (16-30 nt) was performed using fragmentation buffer (Ambion, USA), followed with purification, enrichment, ligation (with 3' and 5' RNA adapters) and PCR amplification. The finally purified amplification products were regarded small RNA libraries $(n=24)$ used for miRNA-seq. For the preparation of the mRNA-seq, total RNA was reverse transcribed to the first strand cDNA using SuperScript III reverse transcriptase (Invitrogen) with 6-base random primers. The DNA samples were used for the mRNA-seq library $(n=24)$ construction following the instruction from the mRNA-Seq Sample Preparation Kit (Illumina, USA). Illumina HiSeq 4000 sequencing platforms (pair-end $2 \times 150 \mathrm{bp}$ for mRNA-seq, and singleend $50 \mathrm{bp}$ for miRNA-seq) were used for the sequencing analysis.

\section{Data processing}

The raw sequencing data in the format of FastQ were quality-controlled using the FastQC (version 0.11.5, http://www.bioinformatics.babraham.ac.uk/projects/ fastqc/) by removing the low quality reads and adaptor reads. 


\section{mRNA profiling}

The clean reads assembled and aligned to the reference genome sequence (http://rice.plantbiology.msu.edu/pub/ data/Eukaryotic_Projects/o_sativa/; IRGSP-1.0.28) was conducted using hisat2 [70]. The reads numbers were counted by htseq-count [71]. Cufflinks (version 2.2.1) [72] was used for the quantitative analysis of the reads by calculating the FPKM values (expected number of Fragments Per kb per Millions reads) of reads in each sample. Principal component analysis (PCA) and sample-to-sample clustering analysis were performed based on the FPKM of reads. The DEGs were identified using DESeq (http://bioconductor.org/packages/release/ bioc/html/DESeq.html) [73] by pairwise comparison. DEGs were identified using the Negative binomial distribution test with the criteria of $p$ value $<0.05$ and $\mid \log _{2}(-$ Fold Change, FC) $\mid \geq 1$. Up- and down-regulated DEGs were identified as $\log _{2} \mathrm{FC}>1$ and $\log _{2} \mathrm{FC}<-1$, respectively. The expression profiles of DEGs were presented using hierarchical clustering by pheatmap (version 1.0.10; https://cran.r-project.org/web/packages/pheatmap/index.html).

\section{miRNA profile analysis}

The clean reads generated by miRNA-seq were aligned with the reference genome sequence (O. sativa; http:// www.mirbase.org/cgi-bin/mirna_summary.pl?org=osa). Small RNA annotation and assignment (rRNA, snRNA, snoRNA and tRNA) were conducted in Rfam [74], cDNA sequencing, species repeat library [75] and miRBase [76, 77]. Small RNA sequences $(>26 \mathrm{nt})$ were removed using Bowtie [78]. Sequences in the length of 15-26 nt and those unable to match the mRNA transcripts were used for the identification of known and novel miRNAs after removing the repetitive sequences. Novel miRNAs were identified using Mirdeep2 software [79] and RNAfold [80]. The expression of miRNAs were calculated using transcript per million (TPM). PCA and sample-to-sample clustering analyses were performed based on the expression levels. Differentially expressed miRNAs (DEmiRNAs) in response to $\mathrm{Cd}$ stimulus were identified using DESeq [73] by pairwise comparison methods, with the threshold of $p$ value $<0.05$ and $\mid \log 2$ (Fold change, FC) $\mid \geq 0.5$. Subsequently, the predictive mRNAs of DEmiRNAs were identified using targetfinder [81]. The overlapping DEGs between DEmiRNAs' targets were used for further enrichment analysis.

\section{Enrichment analysis}

The DEGs and overlapping DEGs between DEmiRNAs' targets were separately subjected to the enrichment analysis of Gene Ontoloy (GO; http://www.Geneontology.org/ ) and KEGG (Kyoto Encyclopedia of Genes and Genomes) pathways [82]. GO categories (biological processes, BP; molecular functions, MFs; and cellular components, CCs) and KEGG pathways related to the DEGs were identified with the criterion of $p<0.05$. The miRNA-gene regulatory network was constructed using Cytoscape (version 2.8) [83].

\section{qRT-PCR verification of RNA-seq data}

qRT-PCR analysis was performed on a Light Cycler system (Roche) using a SYBR Green PCR Kit (Qiagen). PCR amplification was performed under the following conditions: $94{ }^{\circ} \mathrm{C}$ for $5 \mathrm{~min}$, followed by 40 cycles of $94{ }^{\circ} \mathrm{C}$ for $15 \mathrm{~s}, 58^{\circ} \mathrm{C}$ for $15 \mathrm{~s}$, and $72{ }^{\circ} \mathrm{C}$ for $20 \mathrm{~s}$ and a final extension at $72^{\circ} \mathrm{C}$ for $5 \mathrm{~min}$. Quantification of gene expression was performed by the comparative $2^{-\Delta \Delta C} \mathrm{~T}$ method. The validation analysis was performed with three independent biological replicates. The genespecific primers for qRT-PCR were designed using Primer Premier 5.0 (http://www.PremierBiosoft.com) and were synthesized by Invitrogen (Carlsbad, USA). The correlation analysis of qRT-PCR and RNA-seq were based on Pearson's correlation coefficient. The primer sequence information were listed in Additional file 6: Table S5.

\section{Statistical analysis}

All experimental data were expressed as mean \pm SD . Statistical analysis of all data was performed using the GraphPad Prism 6. Differences were analyzed using the unpaired t-test or one-way ANOVA. $P<0.05$ and $p<$ 0.01 was considered as significant and very significant difference, respectively.

\section{Supplementary information}

Supplementary information accompanies this paper at https://doi.org/10. 1186/s12864-020-6474-7.

Additional file 1: Figure S1. The expression level of candidate genes related to $\mathrm{Cd}$ transport. T, Cd-treatment; $\mathrm{C}$, control; $\mathrm{N}$, node I; $\mathrm{P}$, panicle node; X, Xiangwanxian No. 12; y, Yuzhenxiang.

Additional file 2: Table S1. Statistics of the differentially expressed genes (DEGs) and miRNAs (DEmiRNAs) by different pairwise comparison.

Additional file 3: Table S2. The expression profiles of the 84 common differentially expressed genes associated with "transporter activity" in Fig. $4 \mathrm{~b}$.

Additional file 4: Table S3. The list of 74 common differentially expressed genes related to "response to stimulus" in Fig. 4c.

Additional file 5: Table S4. The list of the differentially expressed miRNAs

Additional file 6: Table S5. The sequences of primers of genes in qRTPCR.

\section{Abbreviations}

"N": Node I; "P": Panicle node; "X": Xiangwanxian No. 12; "y": Yuzhenxiang; BP: Biological processes; C: Control; CC: Cellular components; Cd: Cadmium; DEGs: Differentially expressed genes; GO: Gene Ontoloy; KEGG: Kyoto Encyclopedia of Genes and Genomes; MF: Molecular functions; NGS: Nextgeneration sequencing; PCA: Principle component analysis; T: Cd treatment; TFs: Transcription factors; TPM: Transcript per million 


\section{Acknowledgements}

We deeply thank Prof. Jyanchyun Jang (Ohio State University) for his valuable comments and discussion on previous versions of the manuscript.

\section{Authors' contributions}

$\mathrm{ZZ}$ planted, treated and sampled the rice materials. ZZ and YY performed $\mathrm{Cd}$ concentration analysis. AL designed the experiments, analyzed the results and wrote the manuscript. GC participated in the experimental design and provided technical support. All authors approved the manuscript.

\section{Funding}

This research was financially supported by Integration and Demonstration of Green and Simple Rice Technology in Southern Hunan(2018YFD0301005) and Post Expert Project of Technical System of Rice Industry in Hunan Province. The funder had no roles in the design and conduct of the study; collection, management, analysis and interpretation of the data; preparation, review, or approval of the manuscript; or the decision to submit the manuscript for publication.

\section{Availability of data and materials}

The datasets for this study can be found in the BIG SUB database (https:// bigd.big.ac.cn/gsub/) with the access No. CRA001894 and CRA001895.

\section{Ethics approval and consent to participate}

Not applicable.

\section{Consent for publication}

Not applicable.

\section{Competing interests}

The authors declare that they have no competing interests.

\section{Author details}

${ }^{1}$ College of Bioscience and Biotechnology, Hunan Agricultural University, Changsha, Hunan 410128, People's Republic of China. ${ }^{2}$ College of Agronomy, Hunan Agricultural University, Changsha, Hunan 410128, People's Republic of China. ${ }^{3}$ Southern Regional Collaborative Innovation Center for Grain and Oil Crops (CICGO), Hunan Agricultural University, Changsha 410128, People's Republic of China.

\section{Received: 27 August 2019 Accepted: 9 January 2020}

\section{Published online: 06 February 2020}

\section{References}

1. Wang C, Mo Z, Wang H, Wang Z, Cao Z. The transportation, timedependent distribution of heavy metals in paddy crops. Chemosphere. 2003;50(6):717-23.

2. Wang $\mathrm{M}$, Chen $\mathrm{A}$, Wong $\mathrm{MH}$, Qiu R, Cheng $\mathrm{H}$, Ye Z. Cadmium accumulation in and tolerance of rice (Oryza sativa L.) varieties with different rates of radial oxygen loss. Environ Pollut. 2011;159(6):1730-6.

3. Afzal J, Hu C, Imtiaz M, Elyamine A, Rana M, Imran M, Farag M. Cadmium tolerance in rice cultivars associated with antioxidant enzymes activities and Fe/Zn concentrations. Int J Environ Sci Technol. 2018:1-12. https://www. researchgate.net/publication/328433396_Cadmium_tolerance_in_rice_ cultivars_associated_with_antioxidant_enzymes_activities_and_FeZn_ concentrations

4. Luo JS, Yang Y, Gu T, Wu Z, Zhang Z. The Arabidopsis defensin gene AtPDF2. 5 mediates cadmium tolerance and accumulation. Plant Cell Environ. 2019. https://doi.org/10.1111/pce.13592.

5. Zhang ZH, Zhou T, Tang TL, Song HX, Guan CY, Huang JY, Hua YP. Multiomics landscapes uncover the pivotal role of subcellular reallocation of cadmium in regulating rapeseed resistance to cadmium toxicity. J Exp Bot. 2019:erz295.

6. Huang YY, Shen C, Chen JX, He CT, Zhou Q, Tan X, Yuan JG, Yang ZY. Comparative transcriptome analysis of two Ipomoea aquatica Forsk. Cultivars targeted to explore possible mechanism of genotype-dependent accumulation of cadmium. J Agric Food Chem. 2016;64(25):5241-50.

7. Das N, Bhattacharya S, Maiti MK. Enhanced cadmium accumulation and tolerance in transgenic tobacco overexpressing rice metal tolerance protein gene OsMTP1 is promising for phytoremediation. Plant Physiol Biochem. 2016;105:297-309.
8. Uraguchi S, Fujiwara T. Cadmium transport and tolerance in rice: perspectives for reducing grain cadmium accumulation. Rice. 2012;5(1):5.

9. Chiang HC, Lo JC, Yeh KC. Genes associated with heavy metal tolerance and accumulation in $\mathrm{Zn} / \mathrm{cd}$ hyperaccumulator Arabidopsis halleri: a genomic survey with cDNA microarray. Environ Sci Technol. 2006;40(21):6792-8.

10. Ueno D, Yamaji N, Kono I, Huang CF, Ando T, Yano M, Ma JF. Gene limiting cadmium accumulation in rice. Proc Natl Acad Sci U S A. 2010;107(38):16500-5.

11. Luo JS, Huang J, Zeng DL, Peng JS, Zhang GB, Ma HL, Guan Y, Yi HY, Fu YL, Han B, Lin HX, Qian Q, Gong JM. A defensin-like protein drives cadmium efflux and allocation in rice. Nat Commun. 2018;9(1):645.

12. Yamaji N, Ma JF. The node, a hub for mineral nutrient distribution in graminaceous plants. Trends Plant Sci. 2014;19(9):556-63.

13. Feng X, Han L, Chao D, Liu Y, Zhang Y, Wang R, Guo J, Feng R, Xu Y, Ding $Y$. Ionomic and transcriptomic analysis provides new insight into the distribution and transport of cadmium and arsenic in rice. J Hazard Mater. 2017;331:246-56.

14. Fujimaki S, Suzui N, Ishioka NS, Kawachi N, Ito S, Chino M, Nakamura SI. Tracing cadmium from culture to spikelet: noninvasive imaging and quantitative characterization of absorption, transport, and accumulation of cadmium in an intact rice plant. Plant Physiol. 2010;152(4):1796-806.

15. Yamaji N, Ma JF. Node-controlled allocation of mineral elements in Poaceae. Curr Opin Plant Biol. 2017;39:18-24.

16. Wei D, Yuzhu Z, Hejun A, Baohua F, Yang L, Qiang L. Cadmium accumulation and transfer capacity among different types of Rice cultivars at seedling stage. China Rice. 2018;24:86-90.

17. Takahashi R, Ishimaru Y, Senoura T, Shimo H, Ishikawa S, Arao T, Nakanishi H, Nishizawa NK. The OsNRAMP1 iron transporter is involved in $\mathrm{cd}$ accumulation in rice. J Exp Bot. 2011;62(14):4843-50.

18. Tang L, Mao B, Li Y, Lv Q, Zhang LP, Chen C, He H, Wang W, Zeng X, Shao Y. Knockout of OsNramp5 using the CRISPR/Cas9 system produces low cdaccumulating indica rice without compromising yield. Sci Rep. 2017;7(1):14438.

19. Sui FQ, Chang JD, Tang Z, Liu WJ, Huang XY, Zhao FJ. Nramp5 expression and functionality likely explain higher cadmium uptake in rice than in wheat and maize. Plant Soil. 2018;433(1-2):377-89.

20. Takahashi R, Ishimaru Y, Shimo H, Bashir K, Senoura T, Sugimoto K, Ono K, Suzui N, Kawachi N, Ishii S. From laboratory to field: OsNRAMP5-knockdown rice is a promising candidate for cd phytoremediation in paddy fields. PLoS One. 2014;9(6):e98816.

21. Chen C-Z, LV X-F, Li J-Y, Yi H-Y, Gong J-M. Arabidopsis NRT1.5 is another essential component in the regulation of nitrate reallocation and stress tolerance. Plant Physiol. 2012;159:1582.

22. Chen Y, Zhi J, Zhang H, Li J, Zhao Q, Xu J. Transcriptome analysis of Phytolacca americana L. in response to cadmium stress. PLoS One. 2017;12: e0184681.

23. Zhang Y, Wang Z, Chai TY, Zhensong W, Zhang H. Indian mustard aquaporin improves drought and heavy-metal resistance in tobacco. Mol Biotechnol. 2008;40(3):280-92.

24. Przedpełska-Wąsowicz EM, Wierzbicka M. Gating of aquaporins by heavy metals in Allium cepa L. epidermal cells. Protoplasma. 2011:248(4):663-71.

25. Kholodova V, Volkov K, Abdeyeva A, Kuznetsov V. Water status in Mesembryanthemum crystallinum under heavy metal stress. Environ Exp Bot. 2011;71(3):382-9.

26. Lin $H$, Fang $C-X$, Li $Y$, Lin W, He J, Lin R, Lin W. Cadmium-stress mitigation through gene expression of rice and silicon addition. Plant Growth Regul. 2017:81(1):91-101.

27. Faraji J, Sepehri A. Titanium Dioxide Nanoparticles and Sodium Nitroprusside Alleviate the Adverse Effects of Cadmium Stress on Germination and Seedling Growth of Wheat (Triticum aestivum L.). Univ Sci. 2018;23(1):208.

28. Shahpiri A, Deljoonia R. Enhancement of catalase and superoxide dismutase activities in transgenic Escherichia coli expressing rice metallothionein isoforms. J BioSci Biotechnol. 2018;7(1):5-10.

29. Sebastian A, Prasad M. Exogenous citrate and malate alleviate cadmium stress in Oryza sativa L.: probing role of cadmium localization and iron nutrition. Ecotoxicol Environ Saf. 2018;166:215-22.

30. Gu C, Liu L, Song A, Liu Z, Zhang Y, Huang S. Iris lactea var. chinensis (Fisch.) cysteine-rich gene IICDT1 enhances cadmium tolerance in yeast cells and Arabidopsis thaliana. Ecotoxicol Environ Saf. 2018;157:67-72.

31. Deng F, Yu M, Martinoia E, Song WY. Ideal cereals with lower arsenic and cadmium by accurately enhancing vacuolar sequestration capacity. Front Genet. 2019;10:322. 
32. Song WY, Yamaki T, Yamaji $N$, Ko D, Jung KH, Fujii-Kashino $M, A n G$ Martinoia $E$, Lee $Y$, Ma JF. A rice $A B C$ transporter, OsABCC1, reduces arsenic accumulation in the grain. Proc Natl Acad Sci U S A. 2014; 111(44):15699-704.

33. Hasan SA, Hayat S, Ahmad A. Brassinosteroids protect photosynthetic machinery against the cadmium induced oxidative stress in two tomato cultivars. Chemosphere. 2011;84(10):1446-51.

34. Farooq M, Ali S, Hameed A, Bharwana S, Rizwan M, Ishaque W, Farid M, Mahmood K, lqbal Z. Cadmium stress in cotton seedlings: physiological, photosynthesis and oxidative damages alleviated by glycinebetaine. S Afr J Bot. 2016;104:61-8.

35. Jia H, Wang X, Dou Y, Liu D, Si W, Fang H, Zhao C, Chen S, Xi J, Li J. Hydrogen sulfide-cysteine cycle system enhances cadmium tolerance through alleviating cadmium-induced oxidative stress and ion toxicity in Arabidopsis roots. Sci Rep. 2016;6:39702.

36. Gupta D, Pena LB, Romero-Puertas M, Hernández A, Inouhe M, Sandalio L. NADPH oxidases differentially regulate ROS metabolism and nutrient uptake under cadmium toxicity. Plant Cell Environ. 2017;40(4):509-26.

37. Parker SP, Bowden WB, Flinn MB, Giles CD, Arndt KA, Beneš JP, Jent DG. Effect of particle size and heterogeneity on sediment biofilm metabolism and nutrient uptake scaled using two approaches. Ecosphere. 2018;9(3): e02137.

38. Uraguchi S, Kamiya T, Sakamoto T, Kasai K, Sato Y, Nagamura Y, Yoshida A, Kyozuka J, Ishikawa S, Fujiwara T. Low-affinity cation transporter (OsLCT1) regulates cadmium transport into rice grains. Proc Natl Acad Sci U S A. 2011;108(52):20959-64.

39. Yamaguchi N, Ishikawa S, Abe T, Baba K, Arao T, Terada Y. Role of the node in controlling traffic of cadmium, zinc, and manganese in rice. J Exp Bot. 2012;63(7):2729-37.

40. Shu F, Nobuo S, Ishioka NS, Naoki K, Sayuri I, Mitsuo C, Shin-Ichi N. Tracing cadmium from culture to spikelet: noninvasive imaging and quantitative characterization of absorption, transport, and accumulation of cadmium in an intact rice plant. Plant Physiol. 2010;152(4):1796-806.

41. Baxter I. Should we treat the ionome as a combination of individual elements, or should we be deriving novel combined traits? J Exp Bot. 2015; 66(8):2127-31.

42. Sasaki A, Yamaji N, Yokosho K, Jian FM. Nramp5 is a major transporter responsible for manganese and cadmium uptake in Rice. Plant Cell. 2012; 24(5):2155-67.

43. Zhang $Y, X u Y H, Y i ~ H-Y$, Gong JM. Vacuolar membrane transporters OsVIT1 and OsVIT2 modulate iron translocation between flag leaves and seeds in rice. Plant J Cell Mol Biol. 2012;72(3):400-10.

44. Peng JS, Gong JM. Vacuolar sequestration capacity and long-distance metal transport in plants. Front Plant Sci. 2014;5:19.

45. Connorton JM, Jones ER, Rodríguez-Ramiro I, Fairweather-Tait S, Uauy C, Balk J. Altering expression of a vacuolar iron transporter doubles iron content in white wheat flour. Plant Physiol. 2017;174:2434-44.

46. Deng F, Yamaji N, Ma JF, Lee SK, Jeon JS, Martinoia E, Lee Y, Song WY. Engineering rice with lower grain arsenic. Plant Biotechnol J. 2018;16(10): 1691-9.

47. Li JY, Fu YL, Pike SM, Bao J, Tian W, Zhang Y, Chen CZ, Zhang Y, Li HM, Huang J. The Arabidopsis nitrate transporter NRT1.8 functions in nitrate removal from the xylem sap and mediates cadmium tolerance. Plant Cell. 2010;22(5):1633-46.

48. Mao QQ, Guan MY, Lu KX, Du ST, Fan SK, Ye YQ, Lin XY, Jin CW. Inhibition of nitrate transporter 1.1-controlled nitrate uptake reduces cadmium uptake in Arabidopsis. Plant Physiol. 2014;166(2):933-4.

49. Guan MY, Fan SK, Fang XZ, Jin CW. Modification of nitrate uptake pathway in plants affects the cadmium uptake by roots. Plant Signal Behav. 2015;10: e990794.

50. Mcloughlin F, Basha E, Fowler ME, Kim M, Bordowitz J, Katiyar-Agarwal S, Vierling E. Class I and II small heat-shock proteins protect protein translation factors during heat stress. Plant Physiol. 2016;172(2):00536.02016.

51. Pandey S, Fartyal D, Agarwal A, Shukla T, James D, Kaul T, Negi YK, Arora S, Reddy MK. Abiotic stress tolerance in plants: myriad roles of Ascorbate peroxidase. Front Plant Sci. 2017;8.

52. Park CJ, Seo YS. Heat shock proteins: a review of the molecular chaperones for plant immunity. Plant Pathol J. 2015;31(4):323-33.

53. Cai SY, Zhang Y, Xu YP, Qi ZY, Li MQ, Ahammed GJ, Xia XJ, Shi K, Zhou YH, Reiter RJ. HsfA1a upregulates melatonin biosynthesis to confer cadmium tolerance in tomato plants. J Pineal Res. 2017;62(2):e12387.
54. Reddy GN, Prasad M. Cadmium-induced protein phosphorylation changes in rice (Oryza sativa L.) seedlings. J Plant Physiol. 1995;145(1-2):67-70.

55. Wang A, Yu X, Mao Y, Liu Y, Liu G, Liu Y, Niu X. Overexpression of a small heat-shock-protein gene enhances tolerance to abiotic stresses in rice. Plant Breed. 2015;134(4):384-93.

56. Kozono D, Yasui M. S king L, agre P: aquaporin water channels: atomic structure and molecular dynamics meet clinical medicine. J Clin Invest. 2002;11(109):1395-9.

57. Wan X, Steudle E, Hartung W. Gating of water channels (aquaporins) in cortical cells of young corn roots by mechanical stimuli (pressure pulses): effects of ABA and of $\mathrm{HgCl}_{2}$. J Exp Bot. 2004;55(396):411-322.

58. Steudle $\mathrm{E}$. The cohesion-tension mechanism and the acquisition of water by plant roots. Annu Rev Plant Physiol Plant Mol Biol. 2001;52:847-75.

59. Cheah BH, Nadarajah K, Divate MD, Wickneswari R. Identification of four functionally important microRNA families with contrasting differential expression profiles between drought-tolerant and susceptible rice leaf at vegetative stage. BMC Genomics. 2015;16(1):692.

60. Maeda S, Sakazono S, Masuko-Suzuki H, Taguchi M, Yamamura K, Nagano K, Endo T, Saeki K, Osaka M, Nabemoto M. Comparative analysis of microRNA profiles of rice anthers between cool-sensitive and cool-tolerant cultivars under cool-temperature stress. Genes Genet Syst. 2016:15-00056.

61. Sharma D, Tiwari M, Lakhwani D, Tripathi RD, Trivedi PK. Differential expression of microRNAs by arsenate and arsenite stress in natural accessions of rice. Metallomics. 2015;7(1):174-87.

62. Wei L, Zhang D, Xiang F, Zhang Z. Differentially expressed miRNAs potentially involved in the regulation of defense mechanism to drought stress in maize seedlings. Int J Plant Sci. 2009;170(8):979-89.

63. DalCorso G, Farinati S, Furini A. Regulatory networks of cadmium stress in plants. Plant Signal Behav. 2010;5(6):663-7.

64. Sun L, Wang J, Song K, Sun Y, Qin Q, Xue Y. Transcriptome analysis of rice (Oryza sativa L.) shoots responsive to cadmium stress. Sci Rep. 2019;9(1):10177.

65. Shen Q, Liu Z, Song F, Xie Q, Hanley-Bowdoin L, Zhou X. Tomato SISnRK1 protein interacts with and Phosphorylates $\beta C 1$, a pathogenesis protein encoded by a Geminivirus $\beta$-satellite. Plant Physiol. 2011;3(157):1394-406.

66. Hao L, Wang H, Sunter G, Bisaro DM. Geminivirus AL2 and L2 proteins interact with and inactivate SNF1 kinase. Plant Cell. 2003;15(4):1034-48.

67. Slocombe SP, Beaudoin F, Donaghy PG, Hardie DG, Dickinson JR, Halford NG. SNF1-related protein kinase (snRK1) phosphorylates class I heat shock protein. Plant Physiol Biochem. 2004;42(2):111-6.

68. Testerink C, Dekker HL, Lim ZY, Johns MK, Holmes AB, Koster CG, Ktistakis NT, Munnik T. Isolation and identification of phosphatidic acid targets from plants. Plant J. 2004;39(4):527-36.

69. Cheng W, Yao H, Zhang G, Meiling T. Effects of cadmium stress on rice growth and nutrient metabolism. Chin Agric Sci. 2005;38(3):528-37.

70. Kim D, Langmead B, Salzberg SL. HISAT: a fast spliced aligner with low memory requirements. Nat Methods. 2015;12(4):357.

71. Anders S, Pyl PT, Huber W. HTSeq - a Python framework to work with highthroughput sequencing data. Bioinformatics. 2015;31(2):166-9.

72. Roberts A, Trapnell C, Donaghey J, Rinn JL, Pachter L. Improving RNA-Seq expression estimates by correcting for fragment bias. Genome Biol. 2011; 12(3):R22.

73. Anders S. Analysing RNA-Seq data with the DESeq package. Mol Biol. 2010; 43(4):1-17.

74. Griffiths-Jones S, Bateman A, Marshall M, Khanna A, Eddy SR. Rfam: an RNA family database. Nucleic Acids Res. 2003;31(1):439-41.

75. Chen N. Using RepeatMasker to identify repetitive elements in genomic sequences. Curr Protoc Bioinformatics. 2004;5(1):4.10. 11-14.10. 14.

76. Griffiths-Jones S, Saini HK, van Dongen S, Enright AJ. miRBase: tools for microRNA genomics. Nucleic Acids Res. 2007;36(suppl_1):D154-8.

77. Griffiths-Jones S, Grocock RJ, Van Dongen S, Bateman A, Enright AJ. miRBase: microRNA sequences, targets and gene nomenclature. Nucleic Acids Res. 2006;34(suppl_1):D140-4.

78. Langmead B, Salzberg SL. Fast gapped-read alignment with bowtie 2. Nat Methods. 2012;9(4):357.

79. Friedländer MR, Mackowiak SD, Li N, Chen W, Rajewsky N. miRDeep2 accurately identifies known and hundreds of novel microRNA genes in seven animal clades. Nucleic Acids Res. 2011;40(1):37-52.

80. Denman RB. Using RNAFOLD to predict the activity of small catalytic RNAs. Biotechniques. 1993;15(6):1090-5.

81. Fahlgren N, Carrington JC. miRNA target prediction in plants. Plant MicroRNAs. 2009;592:51-7. 
82. Kanehisa M, Araki M, Goto S, Hattori M, Hirakawa M, Itoh M, Katayama T, Kawashima S, Okuda S, Tokimatsu T. KEGG for linking genomes to life and the environment. Nucleic Acids Res. 2007;36(suppl_1):D480-4.

83. Smoot ME, Ono K, Ruscheinski J, Wang P-L, Ideker T. Cytoscape 2.8: new features for data integration and network visualization. Bioinformatics. 2010; 27(3):431-2.

\section{Publisher's Note}

Springer Nature remains neutral with regard to jurisdictional claims in published maps and institutional affiliations.

Ready to submit your research? Choose BMC and benefit from:

- fast, convenient online submission

- thorough peer review by experienced researchers in your field

- rapid publication on acceptance

- support for research data, including large and complex data types

- gold Open Access which fosters wider collaboration and increased citations

- maximum visibility for your research: over $100 \mathrm{M}$ website views per year

At $\mathrm{BMC}$, research is always in progress.

Learn more biomedcentral.com/submissions 